\title{
Narrative language development of Persian-English bilingual children attending an immersion preschool
}

\author{
Bita Payesteh', Lizbeth H. Finestack² \\ ${ }^{1}$ Department of Communication Sciences and Oral Health, Texas Woman's University, Denton, Texas; ${ }^{2}$ Department of Speech-Language-Hearing \\ Sciences, University of Minnesota - Twin Cities, Minneapolis, Minnesota, United States
}

Purpose: This study aimed to provide a better understanding of the language development of bilingual children who attend a Persian immersion preschool in the United States, with a specific focus on their microstructural language skills derived from a story retell task.

Methods: Participants included two groups of preschoolers: 14 Persian-English bilingual children who attended a Persian immersion preschool (2- through 5-years of age) and 16 monolingual English-speaking children who attended an English-only preschool (3- through 5-years of age). Participants completed a story retell task, and their parents completed a questionnaire regarding their child's language environment.

Results: Analyses revealed that Persian-English bilingual children produced narratives that are comparable to their same-aged, English monolingual peers with regard to measures of microstructure. Furthermore, mean length of utterance in morphemes was significantly associated with parental language input, positively with Persian input, and negatively with English input.

Conclusions: Findings demonstrate that Persian-English bilingual children who attend a Persian immersion preschool develop English to a level comparable to same-age English monolingual peers based on language produced during a story retell task.

Keywords: Preschool language; Persian-English bilinguals; Bilingualism; Immersion schools; Multilingualism

\section{INTRODUCTION}

Language input and production influence children's language development [1-4]. Children who are multilingual have individual experiences with unique language input and opportunities to use their languages, compared to monolingual children. For monolingual children, their language input and use revolve around one language, the language that tends to be spoken by the majority of people in their environment. One unique subset of multilingual children is those who attend immersion schools. Immersion schools aim to improve children's language skills by increasing the input and production of a language not spoken by the majority of people in a country. For example, in the United States, this would be a language other than English. Relatively little is known regarding the language skills of children who attend immersion schools, particularly those of very young children whose immersion school is supporting a less commonly taught language, such as Persian (also known as Farsi) in the United States. Thus, the overarching goal of the current study was to better understand the language develop-

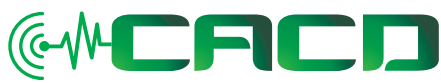

Received: July 7, 2021

Revision: November 12, 2021

Accepted: November 30, 2021

Correspondence:

Bita Payesteh

Correspondence concerning this article should be addressed to Bita Payesteh,

Texas Woman's University - CSOH, P.O.

Box 425737 Denton, TX 76204, United

States

Tel: +940-787-2026

Fax: +940-898-2070

E-mail: bpayesteh@twu.edu

C 2021 The Korean Association of SpeechLanguage Pathologists

This is an Open Access article distributed under the terms of the Creative Commons Attribution NonCommercial License (https://creativecommons.org/ licenses/by-nc/4.0/) which permits unrestricted noncommercial use, distribution, and reproduction in any medium, provided the original work is properly cited. 
ment of preschool children who attended a Persian immersion school in the United States. There were two main aims of this study. First, to describe the English development of preschool children living in the United States attending a Persian immersion school. Second, to examine if there are differences in the language development of children attending a Persian immersion preschool compared to monolingual peers attending an English-speaking preschool. Results from this study will help guide our understanding of language development of bilingual Persian-English speaking children attending a Persian immersion school, specifically, as well as our understanding of language development associated with immersion school experiences more generally. In turn, this information will aid clinical and educational decisions regarding language weaknesses and impairment when assessing children in language immersion programs.

\section{Global Perspectives of Bilingualism}

Of significant importance are studies from countries and regions around the world to gain a broad perspective on language development. A global perspective is important, particularly because across the regions of the world, multilingualism is viewed differently. In some regions, multiple languages are viewed equitably, multilingualism is encouraged, and students have access to more than one language at school. For example, in Montreal, Canada, French and English have relatively equal status, with bilingual signage around the city and over half of the population being multilingual [5]. While in other regions, one language (e.g., the national language) is promoted with less access to multilingual education. With these differences, variables and contexts should be studied with greater breadth by examining language development across the world.

In the United States, while English is currently the dominant language, linguistic diversity was common in the 1700s and 1800s, as people speaking French, German, Dutch, and Spanish increased. Multilingual education laws were enacted to ensure multilingual education, but by the late 1800s, policymakers began focusing on English as the language that should be taught and used. The Naturalization Act of 1906 made English a requirement for citizenship in the United States, and for the next several decades, more laws were authorized to promote the use and teaching of only English. Since 1906, laws and perceptions have ebbed and flowed, and while other languages do not pose a threat to the English language in the United States and we have learned about the benefits of mul- tilingualism and multilingual education, English-only policies suggest otherwise [6,7]. For example, in 1998, the state of California repealed a multilingual education law, permitting only English instruction in the schools. This was replaced with a law allowing for multilingual education in 2016.

\section{Immersion Programs and Schools}

Some countries have a high number of multilingual schools and programs or introduce second languages relatively early. For example, in Sweden, English is introduced in Grade 1, an optional second language in Grade 6, and a third language in Grade 9 [8]. While the second and third languages are optional, it is reported that the majority of students learn a third language (e.g., $70 \%$ of 9 th grade students in 2017 were also learning French, Spanish, or German) [9]; furthermore, the majority of students (59.3\%) with a native language that is not Swedish participate in native language education [10]. In the United States, the number of multilingual programs has increased only recently. In 2000, there were only about 260 dual language programs in the entire United States [11], but by 2015 there were approximately 3,000 programs [12]. However, that number is not sufficient to reach all multilingual children. One study showed that only about $39 \%$ of dual language learners in the United States were receiving instruction in their primary language [13]. More recent studies reveal consistent patterns: 3,800 bilingual students requiring bilingual special education in New York City were not placed in bilingual classrooms in 2019 [14].

Multilingualism education has well documented benefits [15]. Multi-language programs (of which there are several different types) promote multilingualism, multiculturalism, and multiliteracy. When students are multilingual and can utilize their family's heritage language (sometimes referred to as home language, native language, or mother tongue), they are more likely to be closer to family members [16] with greater cohesion and less conflict [17]. When controlling for socioeconomic level, students in multi-language programs have been found to perform academically similarly to, or better than, their monolingual counterparts [18], with no significant disadvantages [19]. However, there is great variability in languages that have been studied and the amount of language input children receive in each language. Thus, the purpose of the current study was to better understand the language development of Persian-English speaking children in the United States attending a Persian immersion preschool and to examine the relationships between language skills and language input. 


\section{Persian and Persian-English Bilingualism}

Persian is the language most commonly spoken by Iranians in Iran and worldwide but is a less commonly taught language in the United States. It is estimated that the Iranian and IranianAmerican population living in the United States includes 476,967 [20] to 1 million people [21], with most people from the United States Census speaking Persian $(407,586)$ [22]. However, despite the growing number of Persian speakers in the United States, little is known regarding the language development of children learning Persian and English in the United States. Some studies have examined very specific language forms of monolingual Persian-speaking children [2326], but we know of no other studies, aside from our own, that have investigated broader language skills of Persian-English bilingual children in the United States attending a preschool immersion school [27]. The other studies that investigate more specific language forms demonstrate that there are broad similarities in skills and development across languages. For example, Persian-English bilingual children in Canada who demonstrated strong English phonological skills, were stronger at reading in English, similar to their English monolingual peers [23]. Researchers have also found differences in development. For example, a Persian-English bilingual child in Iran developed specific morphemes earlier in Persian than English [28].

Payesteh and Finestack [27] compared Persian and English language performance on standardized assessments of the same group of bilingual Persian-English children included in the present study. Findings indicated that this group of children had stronger performance on assessments of English vocabulary and expressive language than Persian language skills. Additionally, although the assessments used in the study did not include bilingual speakers in their normative samples, the standard scores of the Persian bilingual speakers were all well within the average range. Study results also supported a close relationship between the Persian input children received from their parents and Persian language development, without negative consequence to the development of English. One limitation of the parent study was that it only reported on standardized receptive and expressive assessments of vocabulary and grammar. Thus, the current study extends the scope of the original study by examining the microstructural language (e.g., mean length of utterance, number of different words) derived from English narrative retells of PersianEnglish bilingual children and comparing their performance to that of monolingual English-speaking children.

\section{Narrative Language in Children}

Narrative language is an important aspect of language development in children. In a 15-year longitudinal study [29], narrative ability of children at school entry predicted reading comprehension 10 years later. Researchers have found that error patterns in narratives indicate language impairment in bilingual children [30-35]. Research also indicates that measures of microstructural skills (e.g., number of utterances, syntactic complexity) are strong predictors of language ability in Spanish-English bilingual children [36]. For example, using language samples elicited with wordless picture books, Bedore et al. examined productivity and sentence organization. The productivity measures included number of utterances and number of different words (NDW) produced. The sentence organization measures included mean length of utterance in words (MLU-w) and percentage of grammatical utterances $[37,38]$. Bedore et al. [36] found that language ability based on the Bilingual English Spanish Assessment [39] was highly correlated with all productivity and organization measures (except number of utterances) in English and Spanish. Moreover, performance on the BESA was best accounted for by English MLU, English grammaticality, and Spanish grammaticality. Because of the close association between these measures of productivity and sentence organization and the BESA, we included each of these microstructural measures in the current study.

Although there is an increasing number of investigations of narrative language development of bilingual children, studies have primarily included Spanish-English bilingual children $[36,37,40,41]$. Very few studies have examined the narrative language development of other bilingual populations, such as Persian-English speaking children. Other aspects of language development have been examined in monolingual Persian children [42] and Kurdish-Persian speaking [43] children, but there are no studies to our knowledge investigating the narrative skills of Persian-English bilingual children. Thus, this study aimed to explore the English narrative skills of PersianEnglish bilingual children in the United States and better understand the relationships between language input and development. Specifically, the results of this study will inform speech-language pathologists and other educators regarding the utility of narrative language samples for this population.

\section{Specific Aims}

The specific aims (SA) of this study were to:

1. Describe the English microstructural narrative lan- 
guage skills of Persian-English bilingual children attending a Persian immersion preschool,

2. Compare the English narrative language skills of those bilingual children to that of their English monolingual peers, and

3. Assess the relationships of parental language input and child language use with English narrative language skills.

\section{METHODS}

\section{Participants}

This study was approved by the Institutional Review Board at the University of Minnesota and the participating preschools. As part of a larger study, we examined the narrative language skills of two sets of preschoolers. Participants included Persian-English bilingual (BI) children $\left(n=14, M_{\text {age }}=4.1\right.$ years, age range: 2;5 (years;months) to 5;7), who attended a Persian immersion preschool. These participants were the same as those included in the Payesteh and Finestack [27] study. The BI children came from homes where, primarily, one parent spoke Persian and one parent spoke English (in this study, each home included a mother and father). About two-thirds of mothers identified as simultaneous Persian-English bilinguals or native-Persian speakers, and just over one-third of fathers identified as simultaneous Persian-English bilinguals or native-Persian speakers. Median household income for all families was above the United States median, 13 of 14 mothers held at least a bachelor's degree, and 14 of 14 fathers held at least a bachelor's degree.

The comparison group included monolingual Englishspeaking (MO) children ( $n=16, M_{\text {age }}=3.9$ years, age range 2;2 to $5 ; 11)$ who attended an English-only preschool. The MO children came from homes where parents/guardians used English. All but one family had incomes above the United States median, 13 of 16 mothers held at least a bachelor's degree, and 14 of 16 fathers held at least a bachelor's degree.

\section{Schools}

The Persian immersion preschool was a Montessori- and Waldorf-style school that served children ages 2 through 5 years. The school's curriculum was delivered entirely in Persian with native Persian speaking teachers and focused on teaching and advancing the Persian language and culture to preserve this minoritized culture in the United States. Children entered the school with varying levels of Persian lan- guage ability, as they came from diverse homes. The Englishonly school was a Montessori-style school that served children 6 weeks through pre-kindergarten.

\section{Study Tasks and Procedures \\ Parent Questionnaire}

All parents completed a questionnaire, used in Payesteh and Finestack [27] and modeled after Kan [44], Pham [45], and McLinden [46], noting their child's language use and skills, as well as confirming neurotypical development and the absence of language disorders. Additionally, parents of the BI participants completed questions regarding their child's language environment and use (e.g., how much parents spoke each language to the child, how much the child spoke in each language).

\section{Language Tasks}

Each participant completed a battery of language tasks, which included a narrative story retell in English. Participants in the BI group retold two stories based on the wordless picture books Frog, Where Are You? (FWAY) [47] and Frog Goes to Dinner (FGTD) [48]. We randomized and counterbalanced the stories such that half of the participants were randomly selected to retell FWAY in English and the other half retold FGTD in English. This ensured that any differences in the retells across the languages were not due to differences in story difficulty. The order of whether the participants retold the story in Persian or English first was also randomized (e.g., half of the participants completed the Persian tasks first), and the two different languages were tested on different days by different examiners. The current study analyses only included the English narratives of the BI group. Participants in the MO group retold one of the two stories, which was also randomized and counterbalanced.

Narrative scripts. Study scripts for FGTD were based on those available from SALT Software, LLC (www.saltsoftware. com) and the script for FWAY from Kohnert, Kan, and Conboy [49]. These were simplified to ensure they were appropriate for the younger participants in the study. The scripts for the two stories were also created to ensure that the total number of utterances (TNU - FGTD: 35 utterances; FWAY: 30 utterances), mean length of utterance in morphemes (MLU-mFGTD: 8.43; FWAY: 9.60), number of different words (NDWFGTD: 109; FWAY: 108), and total number of words (TNWFGTD: 295; FWAY: 288) were comparable. 


\section{Study Procedures}

During data collection, the examiner told the model story to each participant, using the appropriate story script, and then asked the child to retell the story in their own words, using the book as a visual cue. Tasks were administered by the first author and trained undergraduate speech-language pathology students. Participants' story retells were audio-recorded, then transcribed using standard conventions of the Systematic Analysis of Language Transcripts [50]. Two research assistants transcribed the narratives independently and came to a $100 \%$ consensus; the authors also reviewed every transcript to ensure consistency and accuracy.

\section{Dependent Measures}

\section{Language Input and Production}

Parental language input was calculated as the time parents spoke to their child in Persian and/or English. Parents reported time as a percentage for weekdays and weekend days in each language. Weekday and weekend days were weighted accordingly and calculated into one percentage for English and one percentage for Persian per parent. Then the parents' percentages were averaged to create one percentage of input in Persian and one percentage of input in English per participant. This procedure was used by Payesteh and Finestack [26] and is similar to those used by Marchman, Martinez-Sussman, and Dale [51] and Marchman, Fernald, and Hurtado [52].

Child language production was calculated as time participants spoke Persian and/or English. Parents estimated the time their child spent speaking each language for weekdays and weekend days, across different settings, such as at home, with siblings, reading with parents as in Kan [44]. School was included as a setting because some parents noted that their child spoke English at school, for example, while playing outside with friends. The aforementioned procedure was used to calculate production percentages.

\section{Microstructure Measures}

The following microstructure measures derived from the narrative samples were obtained using SALT Software: TNU, MLU-m, TNW, NDW, and type-token ratio (TTR). We based the measures on SALT's "Analysis Set," meaning that only complete and intelligible utterances were included in the calculations, excluding abandoned and unintelligible utterances. These measures reflect syntactic complexity (e.g., MLU-m), lexical diversity (e.g., NDW, TTR), and overall language pro- duction (e.g., TNW, TNU) and are commonly used in clinical practice and research with both monolingual and multilingual children [53].

\section{Analyses}

For the exploration of the BI participants' narratives skills (Specific Aim 1), microstructural measures were derived using SALT Software; group means and standard deviation were calculated, as well. For the comparisons of the BI and MO groups (Specific Aim 2), two-sample $t$-tests were conducted. Cohen's $d$ was calculated to indicate the effect size of each comparison, with large effect size defined as $d=0.8$, moderate effect size of $d=0.5$, and small effect size of $d=0.2$ [54]. Pearson's correlations were used to examine the relationships across age, English microstructural measures, and language input and use (Specific Aim 3). All data were analyzed in SPSS v25 [55], with $p<0.05$ to determine statistical significance.

\section{RESULTS}

\section{English Narrative Language Skills}

To address Specific Aim 1, we examined the narrative microstructural skills for each individual participant and by age group. For each participant, a microstructural narrative profile was developed (Table 1), which included MLU-m, TNW, TNU, NDW, and TTR. A wide range of performance was found across the microstructural measures; however, all participants performed at or above the expected level for their age. Examination of participants' narrative profiles revealed conformity to the overall group pattern of performance. See Table 1 for group means by age.

\section{Group Comparisons}

Prior to addressing Specific Aim 2, we determined that there were no statistically significant differences between the BI and MO groups based on socioeconomic status (SES), as measured by income level; and parental education, as measured by the degree obtained by each parent. Next, we compared the narrative performance of the BI participants to that of the MO participants using two-sample $t$-tests. As shown in Table 2 , results revealed no significant differences between the BI and MO groups for four of the five microstructure measures analyzed: TNW, TNU, NDW, and TTR. There was a significant $\mathrm{BI}$ and MO group difference based on MLU-m, $t=2.4, p<0.05$, which was associated with a large effect size $(d=0.89)$. This was characterized by the BI group having a higher average 
Table 1. Microstructure of English Narratives for BI and MO Participants

\begin{tabular}{|c|c|c|c|c|c|c|c|c|c|c|c|c|c|c|}
\hline \multirow[b]{2}{*}{ Group } & \multicolumn{7}{|c|}{ BI Participants } & \multicolumn{7}{|c|}{ M0 Participants } \\
\hline & ID & $\begin{array}{l}\text { Age } \\
\text { (mo) }\end{array}$ & MLU-M & TNW & TNU & NDW & TTR & ID & $\begin{array}{l}\text { Age } \\
\text { (mo) }\end{array}$ & MLU-M & TNW & TNU & NDW & TTR \\
\hline \multirow[t]{4}{*}{ 2-3 Years } & Bl 1 & 29 & 3.20 & 15 & 5 & 12 & 0.80 & M01 & 26 & 2.50 & 34 & 14 & 17 & 0.50 \\
\hline & Bl 2 & 30 & 4.40 & 105 & 25 & 59 & 0.56 & M02 & 29 & 3.26 & 73 & 27 & 42 & 0.58 \\
\hline & $\mathrm{Bl} 3$ & 34 & 5.23 & 214 & 43 & 76 & 0.36 & M03 & 30 & 4.70 & 88 & 20 & 46 & 0.52 \\
\hline & Bl 4 & 35 & 5.50 & 131 & 26 & 60 & 0.46 & M04 & 35 & 4.43 & 53 & 14 & 35 & 0.66 \\
\hline Group Means (SD) & & & $\begin{array}{c}4.58 \\
(1.03)\end{array}$ & $\begin{array}{l}116.25 \\
(81.97)\end{array}$ & $\begin{array}{c}24.75 \\
(15.54)\end{array}$ & $\begin{array}{c}51.75 \\
(27.62)\end{array}$ & $\begin{array}{c}0.55 \\
(0.19)\end{array}$ & & & $\begin{array}{c}3.72 \\
(1.03)\end{array}$ & $\begin{array}{c}62 \\
(23.54)\end{array}$ & $\begin{array}{l}18.75 \\
(6.18)\end{array}$ & $\begin{array}{c}35 \\
(12.83)\end{array}$ & $\begin{array}{c}0.57 \\
(0.07)\end{array}$ \\
\hline \multirow[t]{6}{*}{ 3-4 Years } & $\mathrm{Bl} 5$ & 45 & 6.69 & 77 & 13 & 48 & 0.62 & M05 & 38 & 4.54 & 261 & 67 & 101 & 0.39 \\
\hline & $\mathrm{Bl} 6$ & 47 & 4.74 & 81 & 19 & 51 & 0.63 & M06 & 38 & 4.46 & 103 & 26 & 51 & 0.50 \\
\hline & $\mathrm{Bl} 7$ & 47 & 5.89 & 104 & 19 & 54 & 0.52 & M07 & 39 & 6.83 & 143 & 23 & 60 & 0.42 \\
\hline & & & & & & & & M08 & 40 & 3.84 & 193 & 56 & 84 & 0.44 \\
\hline & & & & & & & & M09 & 42 & 4.77 & 171 & 39 & 78 & 0.46 \\
\hline & & & & & & & & M010 & 47 & 3.90 & 107 & 31 & 57 & 0.53 \\
\hline Group Means (SD) & & & $\begin{array}{c}5.77 \\
(0.98)\end{array}$ & $\begin{array}{c}87.33 \\
(14.57)\end{array}$ & $\begin{array}{c}17 \\
(3.46)\end{array}$ & $\begin{array}{l}51 \\
\text { (3) }\end{array}$ & $\begin{array}{c}0.59 \\
(0.06)\end{array}$ & & & $\begin{array}{c}4.72 \\
(1.10)\end{array}$ & $\begin{array}{c}163 \\
(59.50)\end{array}$ & $\begin{array}{c}40.33 \\
(17.61)\end{array}$ & $\begin{array}{c}71.83 \\
(19.14)\end{array}$ & $\begin{array}{c}0.46 \\
(0.05)\end{array}$ \\
\hline \multirow[t]{3}{*}{ 4-5 Years } & $\mathrm{Bl} 8$ & 49 & 9.04 & 214 & 26 & 80 & 0.37 & M011 & 56 & 3.18 & 51 & 17 & 32 & 0.63 \\
\hline & $\mathrm{Bl9}$ & 53 & 6.43 & 129 & 21 & 55 & 0.43 & M012 & 56 & 3.00 & 25 & 9 & 20 & 0.80 \\
\hline & $\mathrm{Bl} 10$ & 54 & 5.76 & 174 & 33 & 75 & 0.43 & & & & & & & \\
\hline Group Means (SD) & & & $\begin{array}{c}7.07 \\
(1.73)\end{array}$ & $\begin{array}{l}172.33 \\
(42.52)\end{array}$ & $\begin{array}{l}26.67 \\
(6.03)\end{array}$ & $\begin{array}{c}70 \\
(13.23)\end{array}$ & $\begin{array}{c}0.41 \\
(0.03)\end{array}$ & & & $\begin{array}{c}3.09 \\
(0.13)\end{array}$ & $\begin{array}{c}38.00 \\
(18.38)\end{array}$ & $\begin{array}{l}13.00 \\
(5.66)\end{array}$ & $\begin{array}{l}26.00 \\
(8.49)\end{array}$ & $\begin{array}{c}0.72 \\
(0.12)\end{array}$ \\
\hline \multirow[t]{4}{*}{ 5-6 Years } & Bl11 & 62 & 7.81 & 228 & 31 & 94 & 0.41 & M013 & 60 & 6.68 & 149 & 25 & 61 & 0.41 \\
\hline & $\mathrm{B} 12$ & 65 & 7.74 & 253 & 35 & 93 & 0.37 & M014 & 62 & 8.03 & 232 & 32 & 97 & 0.42 \\
\hline & B13 & 67 & 8.94 & 141 & 17 & 52 & 0.37 & M015 & 64 & 5.88 & 223 & 42 & 96 & 0.43 \\
\hline & B14 & 67 & 7.88 & 312 & 43 & 120 & 0.38 & M016 & 71 & 7.59 & 188 & 27 & 74 & 0.39 \\
\hline Group Means (SD) & & & $\begin{array}{c}8.09 \\
(0.57)\end{array}$ & $\begin{array}{l}233.50 \\
(71.01)\end{array}$ & $\begin{array}{c}31.50 \\
(10.88)\end{array}$ & $\begin{array}{c}89.75 \\
(28.10)\end{array}$ & $\begin{array}{c}0.38 \\
(0.02)\end{array}$ & & & $\begin{array}{c}7.05 \\
(0.96)\end{array}$ & $\begin{array}{c}198 \\
(37.78)\end{array}$ & $\begin{array}{l}31.50 \\
(7.59)\end{array}$ & $\begin{array}{c}82 \\
(17.57)\end{array}$ & $\begin{array}{c}0.41 \\
(0.02)\end{array}$ \\
\hline
\end{tabular}

MLU-M, mean length of utterance in morphemes; TNU, total number of utterances; NDW, number of different words; TNW, total number of words; TTR, typetoken ratio.

Table 2. Comparison of $\mathrm{BI}$ and $\mathrm{MO}$ Groups

\begin{tabular}{|c|c|c|c|c|c|c|c|}
\hline \multicolumn{2}{|c|}{ Microstructure Variables by Group } & \multirow[t]{2}{*}{$\mathrm{N}$} & \multirow[t]{2}{*}{$M$} & \multirow[t]{2}{*}{$S D$} & \multirow{2}{*}{$\begin{array}{c}t \\
2.44\end{array}$} & \multirow{2}{*}{$\begin{array}{c}p \\
0.02\end{array}$} & \multirow{2}{*}{$\begin{array}{r}d \\
0.89\end{array}$} \\
\hline MLU-m & & & & & & & \\
\hline & Bilingual & 14 & 6.38 & 1.74 & & & \\
\hline & Monolingual & 16 & 4.85 & 1.69 & & & \\
\hline \multirow[t]{3}{*}{ TNU } & & & & & -0.78 & 0.44 & 0.29 \\
\hline & Bilingual & 14 & 25.43 & 10.90 & & & \\
\hline & Monolingual & 16 & 29.31 & 15.49 & & & \\
\hline \multirow[t]{3}{*}{ NDW } & & & & & 0.71 & 0.48 & 0.26 \\
\hline & Bilingual & 14 & 66.36 & 26.04 & & & \\
\hline & Monolingual & 16 & 59.44 & 26.96 & & & \\
\hline \multirow[t]{3}{*}{ TNW } & & & & & 0.87 & 0.57 & 0.32 \\
\hline & Bilingual & 14 & 155.57 & 80.68 & & & \\
\hline & Monolingual & 16 & 130.88 & 75.02 & & & \\
\hline \multirow[t]{3}{*}{ TTR } & & & & & -0.58 & 0.57 & 0.02 \\
\hline & Bilingual & 14 & 0.48 & 0.13 & & & \\
\hline & Monolingual & 16 & 0.51 & 0.11 & & & \\
\hline
\end{tabular}

Results are from two-sample t-tests with Cohen's d as the effect size. MLU-M, mean length of utterance in morphemes; TNU, total number of utterances; NDW, number of different words; TNW, total number of words; TTR, type-token ratio. 
MLU-m $(M=6.4, S D=1.74)$ than the MO group $(M=4.9$, $S D=1.68)$.

\section{Factors Related to Narrative Microstructure Measures}

To address Specific Aim 3, we examined the associations between our microstructure measures, child age, parental language input, and child language output (Table 3). Each of the microstructure measures was significantly correlated with age. MLU-m, TNW, and NDW were moderately and positively correlated with age $(r=.49-.67, p<0.01)$, while TTR was nega- tively correlated with age $(r=-0.37, p<0.05)$. Persian parental language input provided by parents had a moderate, positive correlation with MLU-m $(r=0.64, p<0.05)$ and was not significantly correlated with any other microstructure measures. English parental language input provided by parents had a moderate, negative correlation with MLU-m ( $r=-0.64$, $p<0.05)$ and was not significantly correlated with any other microstructure measures. Results revealed that microstructure measures were not correlated with child language production.

Table 3. Correlations between Microstructure Measures and Language Input and Production

\begin{tabular}{|c|c|c|c|c|c|c|c|c|c|c|c|}
\hline & & \multirow[t]{2}{*}{ Age } & \multicolumn{2}{|c|}{$\begin{array}{l}\text { Microstructure } \\
\text { Measures }\end{array}$} & \multirow[b]{2}{*}{ NDW } & \multirow[b]{2}{*}{ TNW } & \multirow[b]{2}{*}{ TTR } & \multicolumn{2}{|c|}{ Parental Input } & \multicolumn{2}{|c|}{ Child Production } \\
\hline & & & TNU & MLU-M & & & & Persian & English & Persian & English \\
\hline \multirow[t]{3}{*}{ Age } & Pearson Correlation & 1 & & & & & & & & & \\
\hline & Sig. (2-tailed) & & & & & & & & & & \\
\hline & $\mathrm{N}$ & 36 & & & & & & & & & \\
\hline \multirow[t]{3}{*}{ TNU } & Pearson Correlation & .115 & 1 & & & & & & & & \\
\hline & Sig. (2-tailed) & .546 & & & & & & & & & \\
\hline & $\mathrm{N}$ & 30 & 30 & & & & & & & & \\
\hline \multirow[t]{3}{*}{ MLU-M } & Pearson Correlation & $.670^{* *}$ & .130 & 1 & & & & & & & \\
\hline & Sig. (2-tailed) & .000 & .494 & & & & & & & & \\
\hline & $\mathrm{N}$ & 30 & 30 & 30 & & & & & & & \\
\hline \multirow[t]{3}{*}{ NDW } & Pearson Correlation & $.491^{* *}$ & $.814^{* *}$ & $.611^{* *}$ & 1 & & & & & & \\
\hline & Sig. (2-tailed) & .006 & .000 & .000 & & & & & & & \\
\hline & $\mathrm{N}$ & 30 & 30 & 30 & 30 & & & & & & \\
\hline \multirow[t]{3}{*}{ TNW } & Pearson Correlation & $.512^{* *}$ & $.794^{* *}$ & $.657^{* *}$ & $.977^{* *}$ & 1 & & & & & \\
\hline & Sig. (2-tailed) & .004 & .000 & .000 & .000 & & & & & & \\
\hline & $\mathrm{N}$ & 30 & 30 & 30 & 30 & 30 & & & & & \\
\hline \multirow[t]{3}{*}{ TTR } & Pearson Correlation & $-.379 *$ & $-.635^{* *}$ & $-.668^{* *}$ & $-.769^{* *}$ & $-.827^{* *}$ & 1 & & & & \\
\hline & Sig. (2-tailed) & .039 & .000 & .000 & .000 & .000 & & & & & \\
\hline & $\mathrm{N}$ & 30 & 30 & 30 & 30 & 30 & 30 & & & & \\
\hline \multirow[t]{3}{*}{ Parental Input, Persian } & Pearson Correlation & .081 & -.332 & $.639^{*}$ & -.223 & .018 & -.367 & 1 & & & \\
\hline & Sig. (2-tailed) & .774 & .319 & .034 & .509 & .957 & .267 & & & & \\
\hline & $\mathrm{N}$ & 15 & 11 & 11 & 11 & 11 & 11 & 15 & & & \\
\hline \multirow[t]{3}{*}{ Parental Input, English } & Pearson Correlation & -.081 & .337 & $-.639^{*}$ & .228 & -.014 & .365 & $-1.000^{* *}$ & 1 & & \\
\hline & Sig. (2-tailed) & .774 & .311 & .034 & .500 & .967 & .269 & .000 & & & \\
\hline & $\mathrm{N}$ & 15 & 11 & 11 & 11 & 11 & 11 & 15 & 15 & & \\
\hline \multirow[t]{3}{*}{ Child Production, Persian } & Pearson Correlation & .032 & -.475 & .364 & -.216 & -.187 & .047 & $.792^{* *}$ & $-.795^{* *}$ & 1 & \\
\hline & Sig. (2-tailed) & .906 & .119 & .245 & .499 & .560 & .884 & .000 & .000 & & \\
\hline & $\mathrm{N}$ & 16 & 12 & 12 & 12 & 12 & 12 & 15 & 15 & 16 & \\
\hline \multirow[t]{3}{*}{ Child Production, English } & Pearson Correlation & -.122 & .417 & -.513 & .038 & .037 & .057 & $-.800^{* *}$ & $.802^{* *}$ & $-.944^{* *}$ & 1 \\
\hline & Sig. (2-tailed) & .653 & .177 & .088 & .906 & .909 & .860 & .000 & .000 & .000 & \\
\hline & $\mathrm{N}$ & 16 & 12 & 12 & 12 & 12 & 12 & 15 & 15 & 16 & 16 \\
\hline
\end{tabular}

TNU, total number of utterances; MLU-M, mean length of utterance in morphemes; NDW, number of different words; TNW, total number of words; TTR, type-token ratio; Parental Input, calculated as the percentage of time parents spoke Persian or English; Child Production, calculated as the percentage of time a child spoke Persian or English. ${ }^{*} p<0.05$, two-tailed. ${ }^{* *} p<0.01$, two-tailed. 


\section{DISCUSSION}

The study aimed to examine the English narrative skills of Persian-English bilingual children and adds to the small body of research on the oral language skills of Persian-English bilingual children [26-28,56].

\section{English Narrative Skills}

Results revealed a wide range of narrative skills, as determined by microstructure measures (Table 1). We note that the BI children produced substantial narratives in English, despite their schooling being entirely in Persian. The MLU-m calculated for each participant's story retell was within the typical range. For example, Brown's morphemes dictate that the average $2 \frac{1}{2} 2$-year-old should have an MLU-m of approximately between 1.5 and 2.2 [57], and the BI participants in that age range had MLU-m that started at 3.2.

\section{Group Comparisons}

When compared with English-speaking monolingual agematched peers (MO), the BI participants did not perform significantly differently based on TNU, TNW, NDW, and TTR. This indicates that the $\mathrm{BI}$ and MO groups were producing narrative story retells that were comparable in terms of their length (i.e., TNU) and lexical diversity (i.e., TNW, NDW, and TTR). Measures of lexical diversity allow us to investigate vocabulary more deeply, with higher ratings of lexical diversity demonstrating a larger vocabulary, as the child is able to use different words throughout their narrative (as opposed to using the same phrases or words). They have also been shown to increase with age and differentiate between disordered and typical language [58,59].

However, there was a significant difference between the two groups when analyzing MLU-m, with the BI group producing an MLU-m (6.4) that was, on average, higher than the MO group (4.9). MLU-m is an average of the length of all of a participant's utterances and reflects syntactic complexity. Overall, participants in the MO were above or within the expected range for MLU-m, but two MO participants had MLU-m values below the expected range for their age. One explanation for this might be insufficient length of sample. The narratives for these two participants were only 9 and 17 utterances long. Because the recommended length of narratives is at least 50 utterances, we likely did not have enough utterances to derive a reliable MLU-m measure [57]. These language samples of shorter length may also affect the group average, which should be considered when comparing the BI and MO groups. More research with larger sample sizes is required to further interpret our findings.

These results align with studies from other regions of the world, which indicate that children can develop appropriate linguistic skills in the majority language of a country even if their schooling is in a different language [15]. Previous research, in conjunction with the current study, provides positive evidence in encouraging the use of heritage languages for multilingual children as well as supporting meaningful and explicit educational support for those languages.

\section{Factors Related to Narrative Microstructure Measures}

There were several notable correlations across our measures. MLU-m, TNW, and NDW each significantly correlated with age, replicating what has been found in previous research $[60,61]$. This means that as children get older, they produce longer and more complex narratives.

Parental language input in Persian and English significantly correlated with MLU-m, positively and negatively, respectively. This means that children who had a greater amount of Persian spoken to them by their parents (i.e., parental input) tended to have higher MLU-m (English), and children who had greater amounts of English parental input tended to have lower MLU-m (English). As a reminder, nearly all participants (BI and MO) had MLU-m values within the expected range for their age. One explanation for this may be that the parents who used a greater amount of English with their child used less complex language, potentially related to reduced proficiency compared to their Persian language ability. In contrast, children of parents who used more Persian may have received more complex language input, which may have cross-linguistic effects on the child's English complexity. Another explanation may be based on linguistic differences. Kazemi and Klee [62] found that their group of monolingual Persian children had higher MLU-m than reports of English monolingual children. Persian is a highly inflected language, where a root word could have several morphemes and a single inflected word could create a complete utterance, and a higher MLU-m in English could be an influence of Persian. Further investigation is needed to expand on these results and better determine the role of language input and production in bilingual children in narrative language skills.

\section{Limitations and Future Directions}

The following limitations should be considered when inter- 
preting the results of the study. First, the small sample size makes it challenging to observe statistical significance and to determine if any one participant is an outlier or simply represents one end of a range. The specific population studied resulted in a small pool from which to recruit. Second, the story retell task was difficult for some younger participants, thus reducing the number of participants available for analyses. Including a greater number of older preschool-aged participants who were more successful with the task would have been beneficial or utilizing a task better suited to the younger children where performance could be compared across tasks. Third, many participants did not produce the recommended minimum number of utterances in their language samples which could have affected the microstructure measures. Fourth, parent questionnaires were not always completed in their entirety or at all, thus limiting our ability to use participant data when analyzing their task performance with parental language input and child language production. A shorter parent questionnaire with more focused questions or one where parents may complete the questionnaire in different formats (e.g., paper, electronic) may allow for greater completion.

\section{Concluding Remarks}

This study adds to a small body of research on Persian-English bilingual children and children who attend language immersion preschools. Findings demonstrate that Persian-English bilingual children who attend a Persian immersion preschool in the United States are capable of learning English to a level comparable to same-age English monolingual peers and can display their language skills in a story retell task. Studies such as this are important for the progress of education, and speech-language pathology more specifically. First, they provide support for multilingualism, helping us extrapolate what has been found with other languages and language pairs to those languages that are less commonly studied. Moreover, researchers can build upon research with typically developing populations to populations with language disorders. This also allows speech-language pathologists to utilize the research to inform practice with culturally and linguistically diverse populations, particularly in differentiating language disorders from language differences. Finally, studies such as this can be used to inform policy regarding cultural and linguistic diversity, meaning we can promote linguistic diversity and equity by endorsing multilingualism and multi-language immersion programs, with the knowledge that children can be successful at communicating in more than one language.

\section{ACKNOWLEDGMENTS}

Data collection was funded by the University of Minnesota. We thank Layla Safinia, Ericka Lynch, and Gina Titus for their assistance with data processing. Our deepest gratitude to the two preschools for allowing us into their spaces and in working with their students, and to all of the participating children and their families, without which this work would not be possible.

\section{REFERENCES}

1. Kohnert K. Bilinguals with primary language impairment. In: De Bot K, Schrauf RW, editors. Language development over the lifespan. New York and London: Routledge; 2009. p. 146-170.

2. Pearson BZ. Social factors in childhood bilingualism in the United States. Applied Psycholinguistics [Internet]. 2007 Jul 11 [cited 2014 Jan 13];28(3):399-410.

3. Hammer CS, Komaroff E, Rodriguez BL, Lopez LM, Scarpino SE, Goldstein B. Predicting Spanish-English Bilingual Children's Language Abilities. Journal of Speech Language and Hearing Research. 2012 Oct 1;55(5):1251.

4. Bohman TM, Bedore LM, Peña ED, Mendez-Perez A, Gillam RB. What you hear and what you say: language performance in Spanish-English bilinguals. International Journal of Bilingual Education and Bilingualism. 2010;13(3):325-344.

5. World Population Review of Montreal, Canada [Internet]. World Population Review. 2016.

6. Wiley TG. The Reemergence of Heritage and Community Language Policy in the U. S. National Spotlight. The Modern Language Journal. 2005;89(4):594-601.

7. Gándara P, Escamilla K. Bilingual and Multilingual Education [Internet]. In: García O, Lin AMY, May S, editors. Bilingual and Multilingual Education. Cham: Springer International Publishing; 2017.

8. Swedish National Agency for Education. Curriculum for the compulsory school, preschool class and school-age educare. 2018.

9. Swedish National Agency for Education. Comparative Figures Database - Foreign Language. 2017.

10. Swedish National Agency for Education. Comparative Figures Database - Native Language. 2017.

11. Wilson DM. Dual Language Programs on the Rise [Internet]. Harvard Education Letter. 2011 [cited 2021 Sep 9].

12. Lam K, Richards E. More US schools teach in English and Spanish, but not enough to help Latino kids [Internet]. USA Today. 2020 [cited 2021 Sep 9].

13. Zehler AM, Fleischman HL, Hopstock PJ, Pendzick ML, Stephenson TG. Descriptive study of services to LEP students and LEP students with disabilities: Findings on special education LEP students. 2003;1-26.

14. Amin R. Many of NYC's bilingual special education students don't get the right services. Remote learning has made it even harder. 
[Internet]. New York: Chalkbeat; 2020 [cited 2021 Sep 9].

15. Baker C. Foundations of bilingual education and bilingualism. Multilingual Matters; 2011.

16. Tseng V, Fuligni AJ. Parent-Adolescent Language Use and Relationships Among Immigrant Families With East Asian, Filipino, and Latin American Backgrounds. Journal of Marriage and Family [Internet]. 2000 May [cited 2014 Jan 12];62(2):465-476.

17. Portes A, Rumbaut RG. Legacies: The story of the immigrant second generation. Univ of California Press; 2001.

18. Thomas WP, Collier VP, Collier K. English learners in North Carolina, 2010. Fairfax, VA: George Mason University A research report provided to North Carolina Department of Public Instruction. Retrieved from http://p1cdn3static sharpschool com/UserFiles/ Servers/Server_4502383/File/NC_ELL_Study_Yr2_Final\% 20Report_Jul27_2011 pd. 2011;(3):1-45.

19. Collier VP, Thomas WP. Validating the Power of Bilingual Schooling: Thirty-Two Years of Large-Scale, Longitudinal Research. Annual Review of Applied Linguistics. 2017;37:203-217.

20. U.S. Census Bureau. Current Population Survey, Annual Social and Economic Supplements [Internet]. 2017 [cited 2017 Jan 3].

21. The Public Affairs Alliance of Iranian Americans. Demographics and Statistics [Internet]. [cited 2018 Mar 31].

22. Ryan C. Language Use in the United States: 2011, American Community Survey Reports [Internet]. U.S. Census Bureau. 2013 [cited 2021 Jun 21]. p. 1-16.

23. Arab-Moghaddam N, Senechal M. Orthographic and phonological processing skills in reading and spelling in Persian/English bilinguals. International Journal of Behavioral Development [Internet]. 2001 Mar 30 [cited 2013 Dec 27];25(2):140-147.

24. Boudaoud M. The variable development of /s/ + consonant onset clusters in Farsi-English interlanguage. Dissertation. 2008.

25. Farsi M, Leila Z. Practical Contrastive Analysis of English and Persian with special emphasis on Relative Clauses. Time Journals of Arts and Educational Research [Internet]. 2013 [cited 2014 Jan 7];1(September):7-9.

26. Foroodi-Nejad F, Paradis J. Crosslinguistic transfer in the acquisition of compound words in Persian-English bilinguals. Bilingualism: Language and Cognition [Internet]. 2009 Oct 16 [cited 2014 Jan 13];12(4):411-427.

27. Payesteh B, Finestack LH. Influences of language input and production on the language skills of Persian-English bilingual immersion preschool children. Journal of Immersion and ContentBased Language Education [Internet]. 2020 Mar 31;8(1):80-106.

28. Keshavarz MH. Morphological Development in the Speech of a Persian-English Bilingual Child. Journal of Psycholinguistic Research [Internet]. 2007 May 15 [cited 2013 Oct 1];36(4):255-272.

29. Suggate S, Schaughency E, McAnally H, Reese E. From infancy to adolescence: The longitudinal links between vocabulary, early literacy skills, oral narrative, and reading comprehension. Cognitive Development [Internet]. 2018 Jul;47(May):82-95.

30. Bedore LM, Leonard LB. Grammatical Morphology Deficits in Spanish-Speaking Children With Specific Language Impairment. Journal of Speech, Language, and Hearing Research [Internet].
2001 Aug;44(4):905-924.

31. Gutiérrez-Clellen VF, Simon-Cereijido G. The Discriminant Accuracy of a Grammatical Measure With Latino English-Speaking Children. Journal of Speech, Language, and Hearing Research [Internet]. 2007 Aug [cited 2013 Oct 9];50(4):968-981.

32. Jacobson PF, Schwartz RG. English Past Tense Use in Bilingual Children With Language Impairment. American Journal of Speech-Language Pathology [Internet]. 2005 Nov;14(4):313-323.

33. Weismer SE, Hesketh LJ. The Impact of Emphatic Stress on Novel Word Learning by Children With Specific Language Impairment. Journal of Speech, Language, and Hearing Research [Internet]. 1998 Dec;41(6):1444-1458.

34. Marchman VA, Wulfeck B, Weismer SE. Morphological Productivity in Children With Normal Language and SLI. Journal of Speech, Language, and Hearing Research [Internet]. 1999 Feb;42(1):206219.

35. Rice ML, Wexler K. Toward Tense as a Clinical Marker of Specific Language Impairment in English-Speaking Children. Journal of Speech, Language, and Hearing Research [Internet]. 1996 Dec;39 (6):1239-1257.

36. Bedore LLM, Peña EDE, Gillam RBR, Ho THT. Language sample measures and language ability in Spanish-English bilingual kindergarteners. Journal of Communication Disorders [Internet]. 2010 [cited 2013 Nov 3];43(6):498-510.

37. Gámez PB, González D. A comparison of narrative skill in Spanish-English bilinguals and their functionally monolingual Spanish-speaking and English-only peers. International Journal of Bilingualism. 2019;23(1):329-348.

38. Gámez PB, Lesaux NK, Rizzo AA. Narrative production skills of language minority learners and their English-only classmates in early adolescence. Applied Psycholinguistics. 2016;37(4):933-961.

39. Peña ED, Gutierrez-Clellen VF, Iglesias A, Goldstein BA, Bedore LM. Bilingual English Spanish Assessment (BESA). 2018.

40. Jacobson PF, Walden PR. Lexical Diversity and Omission Errors as Predictors of Language Ability in the Narratives of Sequential Spanish-English Bilinguals: A Cross-Language Comparison. American Journal of Speech-Language Pathology [Internet]. 2013 Aug [cited 2013 Dec 12];22(3):554-565.

41. Gutiérrez-Clellen VF. Narratives in two languages: Assessing performance of bilingual children. Linguistics and Education [Internet]. 2002 Jun [cited 2013 Oct 2];13(2):175-197.

42. Rezaeian SM, Ahangar AA, Hashemian P, Mazaheri M. Research Paper: Assessing an Eliciting Narrative Tool Used for Studying the Development of Persian-speaking Children's Narrative Discourse Skills. Journal of Modern Rehabilitation [Internet]. 2020;14(1):5568.

43. Shokouhi H, Hemati A. Use of Reference in the Narratives of Kurdish-Persian Bilingual Children. US-China Education Review. 2014 Dec;4(12):848-860.

44. Kan PF. Novel word learning by sequential bilingual children: A longitudinal study [Internet]. Dissertation. 2008 [cited 2013 Oct 16].

45. Pham GT. Dual Language Development among Vietnamese-Eng- 
lish Bilingual Children: Modeling Trajectories and Cross-Linguistic Associations within a Dynamic Systems Framework. Dissertation. 2011.

46. McLinden D. The Performance of Kindergarten Children Attending a Language Immersion School on a Novel Language-Learning Task. 2011.

47. Mayer M. Frog, where are you? New York: Dial Press; 1969.

48. Mayer M. Frog goes to dinner. New York: Dial Press; 1974.

49. Kohnert K, Kan PF, Conboy BT. Lexical and Grammatical Associations in Sequential Bilingual Preschoolers. Journal of Speech, Language, and Hearing Research [Internet]. 2010 Jun [cited 2013 Oct 2];53(3):684-698.

50. Miller JF, Iglesias A. Systematic Analysis of Language Transcripts (SALT) Research Version. Computer Program. Middleton, WI: SALT Software, LLC; 2012.

51. Marchman VA, Martinez-Sussmann C, Dale PS. The languagespecific nature of grammatical development: evidence from bilingual language learners. Developmental Science [Internet]. 2004 Apr;7(2):212-224.

52. Marchman VA, Fernald A, Hurtado N. How vocabulary size in two languages relates to efficiency in spoken word recognition by young Spanish-English bilinguals. Journal of Child Language [Internet]. 2010 Sep 3 [cited 2013 Oct 2];37(4):817-840.

53. Ebert KD. Language Sample Analysis With Bilingual Children. Topics in Language Disorders [Internet]. 2020 Apr;40(2):182-201.

54. Cohen J. Statistical power analysis for the behavioral sciences. 2nd Editio. Hillsdale, NJ: L. Erlbaum Associates; 1988.
55. IBM Corp. IBM SPSS Statistics for Windows, Version 25.0. Armonk, NY: IBM Corp; 2017.

56. Hossein Keshavarz M, Ingram D. The early phonological development of a Farsi-English bilingual child. International Journal of Bilingualism [Internet]. 2002 Sep 22 [cited 2014 Jan 7];6(3):255-269.

57. Paul R, Norbury C, Gosse C. Language Disorders from Infancy Through Adolescence [Internet]. 5th Editio. Language Disorders from Infancy Through Adolescence. Elsevier; 2018.

58. Tilstra J, McMaster K. Productivity, Fluency, and Grammaticality Measures From Narratives. Communication Disorders Quarterly [Internet]. 2007 Nov 30;29(1):43-53.

59. Owen AJ, Leonard LB. Lexical Diversity in the Spontaneous Speech of Children With Specific Language Impairment. Journal of Speech, Language, and Hearing Research [Internet]. 2002 Oct; 45(5):927-937.

60. Miller JF, Chapman RS. The Relation between Age and Mean Length of Utterance in Morphemes. Journal of Speech, Language, and Hearing Research [Internet]. 1981 Jun;24(2):154-161.

61. Justice LM, Bowles RP, Kaderavek JN, Ukrainetz TA, Eisenberg SL, Gillam RB. The Index of Narrative Microstructure: A Clinical Tool for Analyzing School-Age Children's Narrative Performances. American Journal of Speech-Language Pathology [Internet]. 2006 May;15(2):177-191.

62. Kazemi Y, Klee T. Mean Length of Utterance (MLU) in typicallydeveloping 2: 6-5: 6 year-old Persian-speaking children in Iran. 2001;2-3. 